\title{
Discursos sobre Tecnologias: movimentos e rupturas na pesquisa e as narrativas acadêmicas
}

Julio Cesar Roitberg ${ }^{1}$

Discourses on Technology: movements and ruptures in surveys and academic narratives

TORNAGHI, Alberto José da Costa. Escola faz tecnologia, tecnologia faz escola. Rio de Janeiro: COPPE/UFRJ, 2005. 154p. (COPPE/UFRJ, Dr. Sc, Engenharia de Sistemas e Computação, 2007) Tese - Universidade Federal do Rio de Janeiro, COPPE

\section{O objeto metaforizado}

A tese ${ }^{2}$ defendida por Alberto J.C. Tornaghi, em outubro de 2010, "Escola faz tecnologia, tecnologia faz escola", surpreende tanto pelo modo de apresentação da temática quanto pela seleção do objeto e pelo tratamento dos dados levantados. O autor opta pela narrativa, enquanto gênero textual, aliando ao estilo suaves figuras de linguagem e metalinguagem ${ }^{3}$ que o auxiliam, sobremaneira, na descrição dos sujeitos pesquisados (OLIVEIRA; GERALDI, 2010). O autor assemelha a estrutura de seu texto ao cotidiano escolar ao menos nos títulos, substituindo a clássica divisão metodológica ("de pé quebrado") ${ }^{4}$ : uma tendência na produção acadêmica das áreas humanas. Os textos que compõem o estudo tendem mais a ensaios literários do que propriamente a dissertações estritamente denotativas (se fora possível). Apesar da existência de uma autorização desse gênero entre cujos representantes encontram-se Marx, Freud, Foucault, Bordieu, para não citar, na literatura, Humberto Eco com o romance "O Nome da Rosa", em que se resgata o ambiente sociocultural e ideológico da Idade Média e Irin Yalon com "Quando Nietzsche chorou", em que o autor mescla personagens reais com ficção, na Europa do fim do século XIX, ele ainda se depara com certa reserva nos cursos de pós-graduação. Compreendo, entretanto, a resistência a essa modalidade discursiva nos estudos acadêmicos devido à falta tanto de exercícios de produção textual quanto da crítica literária. Segundo Oliveira e Geraldi (2010), as narrativas enquanto gênero a suportar o discurso científico da contemporaneidade são justificáveis no tocante à apreensão das realidades observadas, já que:

A busca por outras formas de conhecer e de expressar os conhecimentos que, assumindo a impossível descrição "neutra e objetiva" de uma realidade preexistente aos sujeitos que nela se inscrevem, requer descobrir/inventar novos modos de ver/ ler/ouvir/sentir o mundo e de narrá-lo e aos diferentes fazeres/saberes/valores e emoções que nele circulam e dialogam (2010, p. 19).

Tornaghi amolda a introdução de sua tese à arquitetura de uma escola, procurando reproduzir o cotidiano, introduzindo algumas diferenciações que atestam sua fidelidade ao referencial pós-moderno, deixando ao leitor a possibilidade da fruição da leitura de acordo com o ideário impressionista, cuja preocupação maior é a de sugerir, ao invés de obliterar a polifonia (MAFFESOLI, 2008), característica de toda obra que se pretenda verossímil, distanciando-se, dessa maneira, das narrativas descritivas do final do século XIX, em que os autores nacionais procuravam seguir as orientações europeias de escrituração literária, nos moldes da descrição

Ci. Huma. e Soc. em Rev., RJ, EDUR, v. 35, n 1, jan / jun, p. 109-114, 2013. 
de objetos, cenas, ambientes personificados em que, no Brasil, Aluísio de Azevedo, com o romance realista-naturalista, avança em seu tempo assegurando que "o cortiço acordava, abrindo, não os olhos, mas a sua infinidade de portas e janelas alinhadas" (AZEVEDO, 1997, p. 30) para a vida. Em seu percurso textual, Tornaghi ensaia ${ }^{5}$ que nesta escola-tese todo caminho é um caminho para observação, no momento em que as TIC são introduzidas no cotidiano de algumas escolas públicas de ensino básico de São Paulo e como estas são modificadas por ela. A fim de dar conta dessa tarefa, o autor passa a acompanhar os gestores, alunos de um curso realizado na modalidade de ensino a distância $(\mathrm{EaD})$, semipresencial, no âmbito do "Projeto de Gestão Escolar e Tecnologias" para o uso das TIC, a fim de receberem capacitação para atuar na rede de educação de SP.

\section{Os objetivos da pesquisa}

Tornaghi, ao tentar responder "o que é a escola" e as alterações que esta sofre ao ser "impactada" pelas TIC enquanto objetivo maior de sua pesquisa, apropria-se dos conceitos de "rizoma" (DELEUSE; GUATARRI, 2000) para dar conta da miríade de significados da categoria "rede": um sistema aberto possibilitaria a interdependência de "artefatos e fatos", de atos e atores representados desde os objetos físicos, como cadeiras, quadros, lâmpadas, passando pelos alunos, professores, gestores, corredores, janelas. Ampliando essa noção, pondera que "a entidade que educa é uma rede que inclui a escola, mas não se encerra nela." (p. 40). Como a cada um daqueles "actantes" convergem os atributos de "nó" e de "rede", o autor opta por se ater aos "nós desta rede-educação", o que ele denomina por "caixa preta". Dessa forma, lança-se à tarefa de abrir e investigar como acontecem as relações no interior das mesmas em uma escola pública de educação básica. Propõe uma escola emancipada que possa construir e assumir sua própria identidade "a partir do diálogo com a realidade em que está inserida." (p. 42). Apesar de sustentado por um referencial teórico crítico, partindo da concepção da escola enquanto aparelho ideológico do estado e atualizando tal viés com a compreensão das correlações de força que lá operam, Tornaghi, propondo uma escola autora bastante suficiente para criar práticas e artefatos e trocá-los com outros, amplifica um dos elementos discursivos que sustentam "o caráter messiânico das tecnologias" (BARRETO, 2010, p. 27) ao reproduzir um "discurso nodal" " que dá suporte à aceitação da "inclusão" enquanto "divisor digital". Tal messianismo, representado pela relação "homem/máquina” (TORNAGHI, 2007, p. 59) construída através de imagens literárias, traduz "a exuberância tecnológica contemporânea", (BARRETO, 2010, p. 59)

\section{O problema que será tratado}

Propondo inicialmente uma discussão ampla a respeito das TIC no cotidiano da escola, percebe-se, talvez em função da narrativa, mais flexível que o texto referencial, uma "ruptura", um "movimento", um "desvio" (KRISTEVA, 1968) que acrescenta a este primeiro objeto de estudo um outro: 1) tecnologias frequentando os bancos escolares; 2) as TIC modificadas pela escola. Iniciando esse movimento/ruptura/desvio no detalhamento do curso para gestores, o autor atravessa as TIC pelo EaD, já que esta deveria ser a modalidade para a capacitação dos alunos, em rede. Lê-se na conclusão da tese que: 
Esta rede tem muitos actantes: se não podemos afirmar que a presença de qualquer deles seja fundamental, é fácil verificar que a rede seria completamente diversa do que é sem a sua presença. Entre elas a tecnologia computacional ligada à Internet (p. 121).

O dinamismo representado por esse movimento que imprime ora velocidade, ora digressões, é realizado, também, em função da narrativa, já que, como a representação através de figuras estilísticas dota o texto de uma intensa polifonia (MAFFESOLI, 2008), dificilmente será atingida pela linguagem referencial. Assim sendo, pode-se compreender, a partir da metáfora do trânsito (tráfego), do veículo (montaria) e da velocidade (bytes), a recuperação do programa do Futurismo italiano de Tommaso Marinetti (1909), expressa em seu "Manifesto", publicado no jornal parisiense "Le Figaro" em 22 de fevereiro de 1909, que propunha uma arte baseada na exaltação da guerra, do militarismo, das fábricas e das máquinas. No plano da linguagem, pregava a destruição da sintaxe, a ausência de limites representados pela pontuação, o que, em função da destinação da tese, não ousou o autor. Cabe a lembrança de que o Futurismo, que se limitou bem mais a uma proposta, encontra-se contextualizado em um período de grande estabilidade econômica e social anterior à Primeira Guerra Mundial (1914-1918). A "belle époque" é caracterizada pelo novo ritmo da vida urbana, representado pela maior rapidez na circulação das informações, a sensação de que se assistia ao fim de uma época, a frustração com os rumos do progresso e a insatisfação com a sociedade, a desconfiança na razão, a impaciência.

\section{Procedimentos de coleta e análise dos dados}

Para coleta e análise dos dados, Tornaghi visitou escolas de três regiões de SP, sendo duas em Taubaté, duas em São Bernardo, no ABC Paulista, e três na região de Tupã, tendo utilizado tanto a análise dos documentos oficiais da Secretaria de Estado de Educação de São Paulo, quanto a grade concebida para o curso objeto da pesquisa, assim como os portfólios dos gestores-alunos, mensagens eletrônicas enquanto entrevistas e, segundo o autor, "um longo questionário" (p. 105) com perguntas semiestruturadas e estruturadas que ele anexa ao final da tese, o que lhe permite concluir o papel protagonizado pelas TIC, sendo que os sujeitos representados pelos professores, segundo o autor, “também” (p. 122) são necessários, transparecendo, assim, a prevalência do primeiro elemento em detrimento do segundo na medida em que o "sintagma incluidor" pressupõe uma hierarquização nas categorias semânticas (BARTHES, 1974).

\section{Relevância}

Ao protagonizar a escola enquanto sujeito, Alberto Tornaghi avança na discussão do perfil do educador da rede pública de ensino com os dados catalogados pelo INEP no período entre 2002 e 2004. Discute os aspectos relacionados à formação dos educadores considerando: 1) função docente no país e nas regiões; 2) grau de formação; 3) indicadores socioculturais relativos ao uso das TIC; 3) infraestrutura das escolas (p. 48). Ao concluir o capítulo anterior, Tornaghi adverte o leitor que ele, assim como em qualquer outro estudo, não escapará à isenção, pois não há nenhuma neutralidade nas análises propostas (p. 47). Concluindo com o já visto em outros trabalhos que as pesquisas "confirmam que há no país enormes diferenças 
regionais e que a necessidade de investimento em formação para professores em serviço é urgente" (p. 56-57), promove a articulação crítica de sua tese, pois ao utilizar dos indicadores oficiais da Unesco que atestam, segundo o autor, a necessidade da formação dos professores, tanto a inicial como a continuada, revela o que transparece a "sociedade do conhecimento", cujo "projeto ideal dos meios de confinamento é 'concentrar; distribuir no espaço; ordenar no espaço; compor no espaço-tempo uma força produtiva cujo efeito deve ser superior à soma das forças elementares',"citando Deleuze e Foucault (p. 59). Para Tornaghi, não há como se pensar em uma reforma estanque da escola. Ela tem de ser pensada e transformada como um todo e nesse todo o próprio sistema capitalista vem a ser posto em xeque o que ele continua argumentando com Louis Althusser, em "Ideologia e aparelhos ideológicos do estado" (p. 62) e dando continuidade com Foucault e Deleuze (p. 63) estudando a "crise das sociedades disciplinares".

\section{Movimentos e rupturas nas narrativas}

Tornaghi, propondo uma pesquisa qualitativa encaminhando a discussão dos "impactos" das TIC em uma escola, acaba focando o EaD, o que já havia sido antecipado pelo autor que, consciente das barreiras a enfrentar tendo optado pela narrativa, antecipa-se ao "colocar um limite para o estudo" (p.2), propondo investigar "como um processo de formação de educadores realizado por meio de programa de Educação a Distância (EaD) mediado pelas TIC pode contribuir para modificar o mito que constitui e dá forma à escola de educação básica?" (p. 2). Se tal "mito" a que se refere o autor é a representação do estado atual da educação básica que "ensina e repete conhecimentos que são produzidos fora de seus muros e pouco valor dá ao conhecimento que produz", a autonomia deve ser buscada na formação através do exercício da autoria experienciado em EaD e TIC a fim de "reconstituir a identidade da escola fazendo dela autora de conhecimentos, autora de fatos $\delta \mathrm{e}$ de artefatos $\delta$." "Em sua biografia, apresentada na tese, Tornaghi relata experiências enquanto pesquisador e autor de materiais para programas do MEC para implementação de EaD como por exemplo, o "Salto para o Futuro" em consórcio com a Fundação Roberto Marinho; e é exatamente essa experiência que ele aproveita como estofo argumentativo (HABERMAS, 2001) de especialista para sua pesquisa acompanhando "gestores de escola da rede pública estadual de São Paulo" (...) em "um programa de formação para gestores escolares para o uso das Tecnologias de Informação e Comunicação", (...) "concebido na modalidade EaD e, naturalmente, fez uso intensivo das TIC." Segundo o autor, no programa para gestores todos utilizariam "fortemente (grifos meus) as TIC" (p. 35). De acordo com Barreto (2010) esta é uma das tendências da pedagogia do consenso: a escola como redentora da sociedade, salvadora e integradora dos indivíduos em desarmonia com o todo social. Essa intensificação do uso das tecnologias revelada nos discursos (BERNSTEIN, 1998) tanto pela fala quanto por documentos oficiais, afina-se com as orientações do Banco Mundial (FONSECA, 1998) para os países em desenvolvimento o que se percebe na reprodução de uma das crenças desenvolvimentistas de que aquelas "geram a possibilidade de comunicação de muitos para muitos", isto é, computadores ligados em rede, em particular à Internet." Além de propalar a "produção simbólica de muitos, de forma ágil, acessível e barata" (grifos meus). Ao aceitar as TIC enquanto categoria responsável por tal "revolução", ainda como suporte para o EaD, transparece a relação intrínseca entre o poder e o controle, já que, "el poder opera siempre 
sobre las relaciones entre categorias, centrándose em las relaciones entre y, desde este modo, el poder estabelece relaciones legítimas de ordem.” (BERNSTEIN, 1998, p. 37). A reconstituição das tecnologias em detrimento das práticas pedagógicas configura a primazia do empirismo e do utilitarismo na educação. Vale, aqui, a ponderação do autor de que "não há neste estudo, nunca há, nenhuma neutralidade" (p. 47), visto que nas TIC "precisamos negociar, conformar e aceitar ser conformados" (grifos meus) por elas. (p. 39). Como a linguagem e a fala estão impregnadas de ideologia refletindo os aspectos do potencial de significado outorgado pelos "especialistas" - aqueles em quem a sociedade confia -, é redundante considerar, na leitura das Diretrizes Curriculares Nacionais enquanto documento oficial para o controle pedagógico, a implementação das TIC ressignificadas para o grau de desenvolvimento em que o país se encontra e para o qual precisa avançar. Justificando as narrativas enquanto modalidade discursiva para os textos acadêmicos, ao se ler as narrativas, além de se perceber "o processo do perito e do filósofo" (CERTEAU, 2008: p. 155), desvelam-se as lutas de poder e processos de dominação.

\section{Referências}

AZEvEDO, A. O cortiço. Chile: Klik editora, 1997: [Col. Livros O Globo, 10]

BARRETO, R. G. Discursos, tecnologias e educação. Rio de Janeiro: Ed. Uerj, 2009.

BARTHES, R. Novos ensaios críticos seguidos de O grau zero da escritura. São Paulo: Editora Cultrix, 1974.

BERNSTEIN, B. Pegagogía, control simbólico e identidad: teoria, investicación y crítica. Madrid: Ediciones Morata, s.l., 1998.

CERTEAU, M. A invenção do cotidiano 1: artes de fazer. 14ª ed. Petrópolis, RJ: Vozes, 2008.

DELEUSE, G.; GUATARRI, F. Mil Platôs, vol. 1: capitalismo e esquizofrenia. Rio de Janeiro: Ed. 34, 2000 [Col. Trans]

FONSECA, M. O Banco Mundial como referência para a justiça social no terceiro mundo: evidências do caso brasileiro" Revista da Faculdade de Educação. São Paulo, vol. 24, n. 1, p. 37-69, jan./jun. 1998.

HABERMAS, J. Teoría de la acción comunicativa, I: racionalidade de la acción y racionalización social. $2^{a}$ edición. España: Taurus Humanidades, 2001.

KRISTEVA, J. História da linguagem. Lisboa: Edições 70, 1969. [Colecção Signos, 6]. Pp. 387-408.

MAFFESOLI, M. Elogio da razão sensível. 4a edição; Petrópolis: Editora Vozes, 2008. 


\section{OLIVEIRA, I. B.; GERALDI, J. W. (Orgs.). Narrativas: outros conhecimentos, outras formas de expressão. Petrópolis: DP ET Alli, 2010.}

\section{(Endnotes)}

1 UFRRJ - Pesquisador colaborador; SEEDUC-RJ - Orientador de Gestão Pedagógica.

2 Tese submetida ao corpo docente da coordenação dos programas de pós-graduação de engenharia da UFRJ, para a obtenção do grau de Doutor em Ciências em Engenharia de Sistemas e Computação.

3 Entende-se por metalinguagem um código em paralelo a explicar a natureza da própria mensagem, p.ex., na explicação do autor: "A algumas palavras e expressões são atribuídos significados particulares. Elas estão seguidas pelo símbolo de nota musical em sobrescrito, " $\delta$ ", e constam do glossário presente nesta tese."

$4 \mathrm{O}$ autor se descreve como "Educador, flautista e poeta. De louco tenho um pouco, de médico, nada." E relata ter se formado em Física, Bacharelado e Licenciatura, pela PUC RJ. Possui mestrado e doutorado em engenharia de sistemas, com pesquisa "em torno da parceria entre tecnologia e educação." Ele, ainda, se diz pertencer à "era do bit lascado" In: http://saladeaulainterativa.pro.br/moodle/user/view.php?id=811\&course=1 Acesso em 5/12/2010

5 Como o autor, naturalmente desenvolve o hábito da escritura por prazer, talvez se tornasse um penoso exercício um estilo acadêmico que o prendesse às formas clássicas. Tornaghi assim se descreve em seu perfil do Twitter: "Educador, usuário contumaz de tecnologias e botões, escrevo de tudo um pouco, poemas em particular e, quando sobra tempo e sopram os ventos, toco alguma música.” In: http://twitter.com/\#!/tornaghi Em 5/12/2010

6 Com a utilização da Análise Crítica do Discurso, tem-se a possibilidade de se perceber as apropriações, ressiginificações e deslocamentos semânticos que dão sustentação à ideologia hegemônica. Os "discursos nodais", conforme Barreto (2010)

7 Tornaghi cria uma simbologia própria para categorizar os termos fatos e artefatos, devido à especialização linguística adquirida no estudo. 